\title{
Comparative Study on the Present Situation in the Development of the Chinese Long River Delta Women Football Team
}

\author{
Hongxia Zhang \\ Physical Education college, Henan University of Science and Technology, Luoyang, China \\ Email: tbshyx1968@163.com
}

Received 2012

\begin{abstract}
Chinese Long River Delta has three Women Football Teams. The present situation of Chinese Long River Delta Women Football Team attending the 2005 spring training was investigated and studied through questionnaires,observations and visiting. The present management system, fund sources, basic conditions of the coaches and players in the Chinese Long River Delta Women Football Teams are clear. It was found that at present the management system of Shanghai and Jiangsu Women football teams are come up to the professional management system. But Zhejiang Women football hasn't been very well popularized. An orderly system of succession hasn't been formed. The unstable coach population requires to be trained and to raise their level. And their manage policy and measures is insufficient compare with Shanghai and Jiangsu women football team.
\end{abstract}

Keywords: The Chinese Long River Delta ;Women Football; Present Situation

\section{Introduction}

Chinese Long River Delta is one of the areas with fastest development of economy and largest total economical scale in our country. Total GDP in 2009 is the first super-trillion U.S. dollars, accounting for $21.4 \%$ of China's GDP, ranking 11th in the world. October Games Group score in three provinces of the sport's overall strength is that Shanghai is No.5, Jiangsu is No.3, Zhejiangis No.8, which is in the forefront. Shanghai Women's movement has been in a leading position in China, who received nearly 30 national championship. In 2009's October Games, Jiangsu Women have made considerable progress, accessing to adult runner-up. Moreover, in the youth group games below 18 years of age, Jiangsu has got women's football championship, Shanghai women's runner-up, Zhejinag women's acciss to twelfth. According to Haigeng spring training in 2010 with three teams during this series of studies, the three provinces should be based on resource sharing, complementary advantages, mutual benefit and common development, jointly promote the development of the Yangtze River Delta Women's Movement, play the Yangtze River Delta geographical region and economic advantages, and learn the successful experiences of the rapid rise of the Jiangsu team in order to improve the overall level of the Yangtze River Delta Women and jointly promote the development of the movement of women's football as a way to explore China's overall development status of their football development of reference.

\section{Subjects and Methods}

\section{Subjects}

The subjects are the three women's football team in 2010 by the Chinese Football Association Women's organizations in Kunming Haigeng national women football camp in Yangtze River Delta ( Shanghai TV station SVA women's football, Jiangsu China and Thailand women's football, Zhejiang
Hangzhou West women's football).

\section{Methods}

1) Literature data method We provide reference basis for text analysis through accessing to literature data so as to understand the domestic and foreign scholars on women's football development research status.

2) Questionnaire survey method

After the questionnaire reliability, validity and related statistical test, we issue related questionnaires to three teams, coaches and athletes. Both recovery rate and efficiency were $100 \%$.

3) Questionnaire Survey Method

We exchange forum with the coaches of three teams and study the correlation between interview and communication with the leadership of the Football Association, Institute of experts, professional football coaches during the research and writing of women's football training period.

4) Questionnaire survey method

We statistically process and analyze the investigation of the acquired data.

\section{The Results and Analysis}

\section{The Basic Situation of the Yangtze River Delta Region Women's Football}

\section{1) The Shanghai Women's Football}

The team was founded in 1984. In December 27, 1998 they changed its name to Shanghai based women's football club. The first team is the Shanghai SVA women's football. Shanghai based women's football has been the China's first-class women's football team for many years, and in the domestic competition it has made a brilliant record. Especially since the club was founded in 2000, 2003, 2004, the team has won the National League three degrees, championship, League three champion, 
created our country women's history record, thus it became our country the only" Grand Slam" team at present. The women's football club built by the Shanghai Municipal Sports School and Shanghai TV station benefited from the promotion of Sports Bureau strong industry management and Shanghai television media. Currently the modern advanced facility somewhere has been made according to the Chinese Football Association for the occupation Club requests in Shanghai Qingpu District Scenic Dianshan Lake, including available one or two, three troops, and office building complex as well as a natural grass, one artificialturf, a piece of land and 6000 square meters of indoor football museum.

\section{2) The Jiangsu Women's Football}

Its full name is Jiangsu Huatai Ladies Footbal Club, the accounting nets school football team, which is founded in 1998 and consists of a few small players who has been in Jiangsu Taizhou city sports school football program short-term training and juvenile athletes at Jiangsu sports school in athletics, volleyball, fencing and other items. Then several players were introduced from Wuhan and Zhejiang to form a team to enter the early in the national youth competition, and in 2000 began to participate in the adult game. This spring, training has got high quality from the coaches to athletes due to their actively training and diligent. As the host of October Games, Jiangsu women's football team has achieved the best results since their establishment ( ranking the fourth ). In October Games they have made adult female runner, young women football championship honors. The team is currently has its own training base in Nanjing, Jiangning and its soft, hardware facilities in the country have come full out in front.

3) The Zhejiang Women's Football

Its full name is the Zhejiang Hangzhou West Women's football team, established in February 5, 2004, and it belongs to the Zhejiang province sports training a group of long-term training team. In 2007 it changed its name as the Hangzhou West Lake women's football. The West Women's foundation still came out in front in the construction of the country female super club. At present, both the West Women's football No.1 and No.2 team training is in the Tonglu stadium. In order to meet the training, the training base was started last year with a billion budget, there will be a stadium with lights and grandstand and 5 training field, in which there is a plastic field. The West Women's consideration is also given to the players amateur life and not only the standardization of training, board and lodging. The club pay a visit to Hangzhou every two weeks with the players, it also held several activities similar to expanding outdoor fun activities, visiting Qiandao Lake. But compared with Shanghai,
Jiangsu on the overall strength, difference is comprehensive. In 2004 the national female ultra league and championship game, although only scoring, it did not record the position ( YOYO fitness failing ) yet even cannot get the preliminaries in October Games. The ten games won the twelfth of youth group (the last one ). The main purpose to participate in this year's spring training is to exercise team for the adjustment of the team, improve their ability after striving for two years ( School of technology and awareness, to improve anti ), something should be done in three years : balance, individual comprehensive technology, defense in place, high success rate, clearness of field team members responsibility. Then it can prepare for the "Twelve National Games" and strive to become the strong team of the women's football.

\section{The Basic Situation of Yangtze River Delta Region Women's Football Coaches}

\section{1)The Shanghai Women's Football}

At the beginning of 2002, the club restarted to appoint the coach group. It made 7 consecutive championships under the coach Lin Zhihua in the match, who hae been considered as best coaches of 2004 female ultra league tournament by the Chinese Football Association. Currently there are 4 coaches, 2 research coaches, 3 university degree person or above, 2 Senior title person, and 2 intermediate title person. There are 4 coaches after association of coaches' post training, among whom there are 3 person in Class A and 1 person in class B

2) The Jiangsu Women's Football

The team's original coach is the national youth team coach Gao Rongming, who has been the women's football coach since the beginning of 1987 in Shaanxi, Sichuan, Shenzhen and other provinces and cities' team as the head coach and has won the national top three place. In recent years, she has always served as the national youth football coach and national team assistant coach. Present coach, Li Hongbing, whose distinctive features of coach work is the strong pertinence, puts the work to be in line with the actual situation. His training methods are combined with theory and practice to explain profound theories in simple language, which are easy to understand, and the players has overcome their blindness to increase awareness after understanding the football rules based on learning tactics and got great training and working effect. In 2009 Li Hongbing obtained the NvChao best coach. Currently there are 4 coaches, 1 university degree person or above, 1 Senior .

Title person. There are 4 coaches after association of coaches' post training, among whom there are 2 person in Class $\mathrm{A}$ and 2 person in class $\mathrm{B}$.

Table 1.

The Yangtze River Delta region women's football team management and funding basic team.

\begin{tabular}{|c|c|c|c|c|c|}
\hline Team name & department & Nature of team & purpose & Source of funds & Annual expenditure \\
\hline $\begin{array}{l}\text { Shanghai SVA } \\
\text { Women Football }\end{array}$ & club & Enterprises & long-term development & $\begin{array}{l}\text { State appropriation enterprise } \\
\text { sponsored }\end{array}$ & $8000000 \sim 10000000$ \\
\hline $\begin{array}{l}\text { Jiangsu Huatai } \\
\text { Women's Sports }\end{array}$ & $\begin{array}{l}\text { Bureau of Jiangsu } \\
\text { Province }\end{array}$ & $\begin{array}{l}\text { state appropriation, } \\
\text { Enterprise }\end{array}$ & long-term development & $\begin{array}{l}\text { State appropriation enterprise } \\
\text { sponsored }\end{array}$ & 6000000 \\
\hline $\begin{array}{l}\text { Zhejiang West Lake } \\
\text { women's Sports }\end{array}$ & $\begin{array}{l}\text { Bureau of Zhejiang } \\
\text { Province }\end{array}$ & $\begin{array}{l}\text { state appropriation } \\
\text { Enterprise }\end{array}$ & long-term development & $\begin{array}{l}\text { State appropriation enterprise } \\
\text { sponsored }\end{array}$ & $\begin{array}{l}1000000+5000000 \text { yuan } \\
\text { Hangzhou West sponsorship }\end{array}$ \\
\hline
\end{tabular}




\section{3) The Zhejiang Women's Football}

Because the team was a young team, it has always changed its coaches and menbers since its establishment. It first hired Shen Lidong coach from the Football Association of Hubei, who has began coaching the Zhejiang women's football since 2004 February. It obtained great progress under the women's football coach Shang Ruihua's guidance in 2007. After the Olympics, Shang Ruihua left the West Women's. Wang Liping served as head coach who has previously served as assistant coach to former international. And her target is the $2009 \mathrm{Na}-$ tional Games Qualifier. At the preliminary round, the West Women's goal is to enter the National Games finals. But in Sichuan and host team's key competition, because of the referee's two missing judgments, Zhejiang women has lost the qualifying with pity. Failed to reach the club 's goal, Wang Liping chose to leave. Then Li Huayun took the women's West pointer who was a former international football player.

\section{The Basic Situation of Yangtze River Delta Region Women's Football Players}

1) The Shanghai Women's Football

Now there exist 25 athletes in Shanghai SVA women's football team. There are more than 20 people, such as Sun Wen, Shui Qingxia and Pu Wei, selected for the national team in the history. Now the average height of the team is 1.70 meters, a maximum of 35 years of age, a minimum of 16 years old, and the average age is 23 years old. Because the national team preparing for the Olympics national youth team for World Youth Championship in 2008, it has been drawn up to 8 players. In the team, there are 12 people with university degree or above and 13 people with secondary education.

2) The Jiangsu Women's Football

Now there are 32 members in Jiangsu Huatai 's team, and it introduced six players from Qingdao and Sichuan in the end of 2002. In 2004 the team introduced international Teng Wei from Beijing, but it is still a young team. The rest of the team are below the age of 24 except that the 3 players are over the age of 27 and the smallest member is only 17 years old, and the average age is 21 years old. now the team's average height is 1.67 meters. Jiangsu Huatai female football has transported many players to all levels of national teams: for example, Weng Xiaojie, Zhang Yanru Ge Yang, Xinzhi Weng and so on are transported to the national youth team who has won the 2004 World Youth Championship runner-up; six person such as Zhang Yanru, Weng Xiaojie, Ma Jun, Guan Jingjing, Wu Min and Xinzhi Weng are in the newly established national team in 2010. In the Team, there are 12 people with university degree or above, 20 people with secondary education.

\section{3) The Zhejiang Women's Football}

Now there are 29 members in Zhejiang Hangzhou West Women Football team, and its average age is 17 years old and the average height is 1.66 metersas well as a maximum age of 20 years and the minimum 15 years. Because team is built in a hurry, the team quality is not high with the low starting point. The main purpose is to exercise the team in the spring training and prepare for the 2010 contest. There is only one national team member, Zhu Qiao, who served as a goalkeeper. Players are mostly students in physical education College of Ningbo University.

\section{The Training and Competition Situation of Yangtze}

\section{River Delta Region Women's Football Team}

Because the three teams are different in management systems, management ways, channels, training properties, composition of the team and their main tasks, there should exist differences in establishing the training target, making training plan, selecting training content and method and training effects. According to the coaches and athletes' interviews we can find that women athletes is later than male soccer players in football training time. The women's football coverage is narrow, thus many women players are from other sports. Although they have good physical quality of football, their technical masteries are uneven, therefore they must spend a lot of time to improve and enhance the technical ability. Training 32 hours Weekly is the longest time in Jiangsu, a minimum of 15 hours in Zhejiang as well as Shanghai for 26 hours.

\section{1) The Shanghai Women's Football}

The Shanghai women's football is made up by province, City Sports Technology Institute ( sports team ) management of the semi-professional or amateur teen girls soccer team. Their training target and task are very clear, i.e. to train develop and transport the talents for the first team. Therefore, they pay much attention to the equipped coaches, who are of political qualification, good business style and high level of professionalism. In the training management and daily management, training is more formal with high quality and the training time can be guaranteed with more than 20 hours in every week training. In order to defend the women's FA Cup,they immediately put on sports clothes on training field after arriving in Kunming with stationary luggage on the first afternoon. Why do they go to train so seriously? Because the emphasis on this year the Association Women's Football is completely different. Every team seizes every minute and second, thus they are certainly no exception. From the female soccer players' personal comprehensive ability performance, Shanghai team is the best one with a leading position in the tactical level, literacy in the whole country. Players are strong in controlling the ball ability individually, teamwork between players is very good, in midfield the organization is capable and passing is in place, and there are a variety of attacking, whose tactics level ranks the forefront in the teams.

\section{2) The Jiangsu Women's Football}

As the Jiangsu team has got great achievements in October Games, it payed close attention to training from the provincial leadership to coaches, it camp up to 32 people to participate in training in the spring. It has 32 hours a week training with warm-up match and teaching competition, whose YOYO test resulted the best. The Jiangsu team has been famous for its full stamina in the whole nation for a long time. The training and competition guiding ideology of the team is to take physics as basis, technology as the means, and use the advanced practice strategy and tactics accorded with their team. They have purposes to strive to follow the existed teams or any othe teams so as to compete and fight the physical fitness and physique in the high-speed motion, and master a variety of football skills and tactics after 1 to 2 years of efforts according to the play methods different situations used in different formations opponents. In other words, to create a physical technology is the team's struggled direction. Jiangsu women's football team is a young team with strong battle effectiveness and cohesion. It can fight a hard battle and it is a young team thus their style is quite hale and hearty. The team has super luxury lineup: from the 
keeper, Zhang Yanru you, Weng Xiaojie ( No1 and No2 national team goalkeepers ) and Ning Zhenyun ( former national team ), the guard line; Xinzhi Weng, Zhou Gaoping (national team main force ), Ruan Xiaoqing, Zhang Wei ( national youth team main force ), and Ge Yang ( former national team ); midfield, Zhu Wei, ( national youth team striker ), Yu Weimin ( ISA period the main national team main force ), and Song Xiaoli; the vanguard line, Ma Jun ( from Jiangsu 3 teams in 3 into the national team, can be competent striker, front waist, back waist and guard ), and Ding Jiahuan ( Elizabeth you selected the national team). Besides some young country members, basically not any team can match it.

\section{3) The Zhejiang Women's Football}

Because the team is the semi professional youth women football team which is administrated jointly with Province Sports Bureau and the enterprise, team menbers were in Ningbo University taking half a day on the literacy class and another half a day for training before 2005. Team members' individual ability is bad and the training quality is not high, thus it is difficult to achieve good results. With Hangzhou West holdings corporate sponsorship, the West Women's Football has made progress quickly, got a good sustainable development and has also attracted many powerful members to join. The the treatment of West Women's football players in the country is the forefront in the country, which is very attractive in the current football environment. The goalkeeper Zhu Qiao is from the Beijing women's football team and was selected in a new national team. Training time there is 15 hours a week or so, players' ages are small and they in thin body, thus training effect is just so-so. The Zhejiang women's football is a new young team, as to this only 3 anniversary of the founding of the club, it is a normative construction team mainly in personnel training with sustainable development. Its first aim is to make known and then seek greater development.

\section{4) Competition}

Competition is a controlled lever to guide training and adjust the training process. According to the present competition system developed by the Chinese Football Association, there are three main events in the women's senior team each year, respectively for the national championship, FA Cup, and female ultra league tournament.

Both Shanghai and Jiangsu have got remarkable achievements. The Shanghai women's football has been a strong veteran player for many years, yet the alternation of the new and the old made the achievement glided somewhat. Young players' condition has bigger fluctuation, and the mentality is not very stable, thus such players occupied a large part in today's Shanghai team. Of course, after several years of temper, and these players continue to grow so that the Shanghai women's football team will open the opponent gap of the strength. Jiangsu women's football is a new force which suddenly rised, walking the grabbed right way from reserve in Jiangsu women's stable development environment, which has 4 echelon. A province-wide recruitment constantly made the prosperity of the women of all ages with talented people in the level of national team. And the Jiangsu women's success also benefited other teams in the development of reference. It is a team based on the development of the cultivation of reserve talents and their own reliable talent. In contrast, the Zhejiang women's football team is a young team, although it has abundant funds and hardware equipment guarantee, it also needs to introduce domestic and foreign outstanding team improve the quality of training to obtain better result. It should draw more lessons of the successful development experience from Shanghai and Jiangsu on the management and training.

\section{Conclusions and Suggestions}

\section{Conclusions}

\section{1) The Shanghai Women's Football}

The Shanghai women's football management system is getting clearer and more and more mature day by day, the professional teams are really enrolled into professional management system. Tactics is mature and stable. Players have good psychological quality and they can take time on various conditions appeared in the field and get the key events of the game, showing good technical and tactical level and quality. Players' ability of controlling the ball is quite good, teamwork between players cooperates well, in midfield the organization is capable and passing is in place, and there are a variety of attacking. The Shanghai team received a good attack effect due to their high technology content, outstanding ability, scoring more staff, coupled with sophisticated style and rich 's attack repertoire in the game .

\section{2) The Jiangsu Women's Football}

There are more young players in Jiangsu women's football team, who are stamina. Some promising young players are gradually growing and have begun to play some important position in the team according to different opponents using corresponding tactics routines when combined with courage, fast, simple, live characteristics of playing. But compared with the old players, they also appears slightly immature in some of the details about adjusting to changing circumstances in the field, and their mutual tacit understanding is not enough. In the actual psychology there exits apparent difference, causing performance instability. We hope that they can gradually form a set of the tactics with formations of complete system through this further run-in work in the cooperation degree and deepen understanding between new and old players, and further strengthen the midfield organization strength and anti consciousness so as to train player both offensive and defensive ability, which can make the team a qualitative leap in the tactical fighting method.

3) The Zhejiang Women's Football

The Zhejiang women's football had already participated in the National Women's Football Super League in 1999, but the present situation is its narrow popularity, no successor, and it hasn't formed a good echelon construction, which will affect the sustainable development of Zhejiang 's women's movement. According to the economic strength of Zhejiang, it is not a problem for Zhejiang Province to start money to set up a women's football team, but it is an urgent problem to solve about how to collocate reasonable configuration of women's soccer characteristic and reform team management system. Based on this, the Zhejiang Provincial Sports Bureau and Football Association of Zhejiang province want to revitalize Zhejiang province women football movement with the help Hangzhou West Group, and they need further study management system from Shanghai and Jiangsu so as to draw lessons of a rapid rise from Jiangsu 's experience.

\section{Suggestions}

Jiangsu women's football team has got many fruits in the 
October Games and support and sponsorship of government and other kinds of business. The Jiangsu team is very sound at all levels of reserve echelon. Now the Jiangsu 's football team has become China's specimens. The Yangtze River Delta region should give full play to regional and economic advantage and get more applications and contractors of large women's football competition events. It can arouse social all circles force to enhance the interest in the development of female soccer and strengthen the news media propaganda to create an atmosphere to promote women's football development in this way.

The three provinces and cities should be based on the principle of resource sharing, complementary advantages, mutual benefit and common development, clear the professional goal of reform, accelerate the process of women's football occupation, strengthen coach and athlete's communication, give more a series of invitational tournament with format diversification, develop the common development of the Yangtze River Delta region of the women's football market with joined efforts, and encourage more people to pay attention to women's footbal.
Thus it can expand the influence of women's movement and stabilize the team to increase in Yangtze River Delta area of women's football in participation, and jointly promote the development of Yangtze River Delta region women's football.

\section{REFERENCES}

Wang Fang.2010 National Women Football Camp Coaches Business Seminar and Training Data Compilation of Chinese Football Association[Z], 2010:P31-44(Ch).

Chen Xiaoke.Our Country High Level Adult Women Football team Current Situation and Countermeasure Research[J],Journal of Beijing Sport University, 2001(12),P555-557(Ch).

Wang Fang,Our Women Football Movement Present Situation and Analysis[J],Journal of Xi'an Physical Education University, 1999,13(4),P16-19(Ch).

Shen Jianguo, Research on the sports resources integration of Yangtze River Delta region[J],Journal of Chengdu Sport University, 2004(2),P27-29. 